\title{
The Effect of Forest Healing Program on the Resilience of Elderly People in Urban Forest
}

\author{
II Derg Han ${ }^{1}$ and Chang-Duck Koo * \\ ${ }^{1}$ Department of Forest Therapy, Graduate School, Chungbuk National University, Cheongju 28644, Korea \\ ${ }^{2}$ Department of Forestry, Chungbuk National University, Cheongju 28644, Korea
}

\begin{abstract}
The purpose of this study is to investigate the effects of forest healing programs in urban forest on resilience improvement of elderly people. Participants were 20 elderly people aged 65 or older. The study site is a city natural park located in the $\mathrm{G}$ city, which has a well-developed walkway along the ridge and valley, as well as on the lakeside. Forest healing programs consisted of four sessions focusing on forest walking and meditation as main activities. The Korean Resilience Quotient- 53 was used to measure the resilience of the elderly before and after the forest healing program. As a result, The resilience of the elderly participated in the forest healing program was improved and the difference was statistically significant. Self-regulation ability and interpersonal ability, which are sub-factors of resilience, were also improved significantly. Positivity was increased also but the difference was not significant. These results suggest that forest healing programs using urban forests can improve the resilience of the elderly, overcome stress and depression, and improve the quality of life. However, there are some limitations to this study. Further investigation is required to determine the difference in program duration, gender and individual variation.
\end{abstract}

Keywords: depressed, forest walking, meditation, quality of life

\section{Introduction}

The ratio of the elderly is rapidly increasing in the Korean population. According to Statistics Korea, the ratio of the elderly population aged 65 and older exceeded $7 \%$ in 2000, and has since increased rapidly. As of 2015, the elderly takes up $12.8 \%$ of the entire population, becoming twice higher in just 15 years. In another 15 years in 2030, 1 out of 4 citizens will be an elderly person (KOSIS, 2018). The suicide rate of the elderly age 75 and older was 160.4 out of 100,000 persons in 2005, which is more than 8 times the OECD average, and the suicide rate is also increasing rapidly in the elderly population age 65 and older (KiHASA, 2010). 33.1\% of them are elders with symptoms of depression, which is one of the major causes of elderly suicide, and depressive symptoms increase with age (KOSIS, 2014). Depression of the elderly is caused by physical changes as well as urbanization, living environment and nuclearized families (Kim, 2013). These statistics all point out that depression is the key factor that increases the risk of suicide. According to Hong (2006), resilience means 'mental resistance' and the power to positively resist to various adversities and hardships. Considering

Received: April 19, 2018, Revised: June 21, 2018, Accepted: July 6, 2018

First author: Il Derg Han, E-mail: hanildd@naver.com, ORCID: 0000-0002-2893-648X

*Corresponding author: Chang-Duck Koo, E-mail: koocdm@chungbuk.ac.kr, ORCID: 0000-0001-9508-8858 
that all humans have this power, resilience may also have a significant effect on the elderly. Park et al. (2014) discovered that higher resilience of the elderly leads to less suicidal ideation.

As such, resilience has a significant meaning and value in terms of the fact that it sets the direction or goal of intervention for the elderly (Jung, 2010). Yoon and Yoon (2017) argue that higher depression leads to lower resilience, which has a mediating effect on increasing suicidal ideation. Therefore, efforts must be made to positively increase resilience of the elderly. Considering that resilience is 'the power to positively adapt to various adversities and hardships one faces' (Kim, 2011), it is the positive energy inside the elderly to adapt. To this end, it is necessary to develop and expand programs to increase resilience.

Recently, as the national demand for the effects of forests on promoting human health and curing diseases, the government, local governments and the private sector are all actively seeking ways to use forests and expand their healing effect. Park and Miyazaki (2008) found out that it is more psychologically soothing to see the landscape in the forest than the city, and that the forest provides therapeutic benefits as stress decreases and immunity increases in the forest. As such, there have been constant attempts to scientifically prove the therapeutic elements of forests, and many studies have been conducted on the benefits of forests. Now forests are receiving attention not only as a place for leisure and relaxation, but also as a place to promote health, heal the body and mind, and cure diseases. Thus, it is becoming necessary to study the effects of forest healing for the elderly, which is socially vulnerable. The area of forests takes up $63.2 \%$ of the national territory in Korea as of the end of 2015 (Korea Forest Service, 2016), and by actively using various stimulations and functions of the forest environment to provide comfort in the body and mind of the elderly, increase immunity and promote health, it will be possible to reduce social costs in the aging society.

There has been increasing interest in forest healing as a healing to promote social health and stabilize the body and mind of the elderly exposed to various problems in the urban environment (Choi, 2013). There are also studies about developing forest healing programs for elderly forest welfare services in the aging society (Kwon and Choi, 2016) and effects of using forest healing to promote mental and physical health of the elderly, which all demand active use of forest healing programs using urban forests accessible for local residents. Urban forests vary depending on the region, but they have various spaces and plantations as well as infrastructures for forest activities, and thus can be used as a healing space for urban dwellers. Therefore, there is a need for good forest healing programs to promote mental health of the elderly using highly accessible urban forests for the elderly that lack activity such as long-distance travel.

This study will analyze the effects of forest healing programs using the healing factors of urban forests on the effects of resilience in the elderly and actively use this in elderly welfare.

\section{Methods}

\section{Subjects and methods}

We explained the objective and overview of this study to members registered on social welfare foundation 00 located in G city, Jeonbuk. Among them, the study was conducted on 20 elderly people aged 65 to 75 who expressed the will to participate voluntarily and submitted a written consent. All subjects had no trouble participating in forest activities, and the experiment was designed to compare the changes in resilience for the experimental group after the forest healing program in order to determine the effects of the forest healing program in an urban forest on resilience. To verify the effects of the program, we conducted a pretest with the resilience questionnaire on October 16, 2017, and carried out the program from October 16 to 27, 2017 for the subjects twice a week, 90 minutes each from 10 a.m. to 11:30 a.m. in total 4 sessions. The posttest was conducted using the same questionnaire as the pretest after the program, and the forest healing program used 
in this study is as shown in Tables 1 and 2. This study was approved by the IRB of Chungbuk National University (CBNU-201709-SB-550-01).

\section{Study area}

The study area is 00 Park located in G city, taking up an area of total 2,574,000m², and it is an urban natural park made up of 24 peaks with an altitude of at least $60 \mathrm{~m}$. There is a lake at the center of the park, and the trails are well formed between the ridges and valleys as well as along the lakeside. The forest trees are mostly 3-5 age groups, and are formed artificially in cypress forest and a mixed forest of soft and hardwood such as pine, cedar, oak, Himalayan cedar, and maple.

Among the places where the forest healing program was held, 'forest walking' was carried out along a relatively gentle trail that starts from the parking lot, goes along the lake and leads to the sports park, with the total length of $1347.7 \mathrm{~m}$, width of $3 \sim 5 \mathrm{~m}$, maximum height of $4 \mathrm{~m}$, and slope of $5.35 \%$. The road surface is wide and well maintained for even the elderly and people with disabilities to use easily and conveniently. There are 22 families and 31 species of vegetation aside from persimmon planted around the trail, and the route also has many wildflowers such as Chinese astilbe, bleeding heart, loosestrife, Siberian chrysanthemum, corydalis, silver leaf and Korean dandelion so that visitors can enjoy being away and beauty as they walk along the forest. The 'forest meditation' is carried out in a forest where visitors can look down on the lake located in the middle of the forest walking path. There is a pavilion set up in a spot with excellent landscape that

Table 1. Forest healing program plan for elderly people in urban forest

\begin{tabular}{cc}
\hline Session & Activity \\
\hline Session 1 & Warming up, Forest walking, Breathing meditation, Sharing thoughts with others \\
\hline Session 2 & Warming up, Forest walking, Communicating with trees, Forest walking meditation, \\
Session 3 & Talking about thankfulness \\
Session 4 & Warming up, Forest walking, Natural oil hand massage, Forest walking meditation \\
\hline
\end{tabular}

Table 2. Activity details of forest healing program for elderly people in urban forest by time and place

\begin{tabular}{|c|c|c|c|}
\hline Program contents & Activity time & Place of activity & Activities \\
\hline Warming up & $10 \mathrm{~min}$ & Entrance plaza & $\begin{array}{c}\text { Hand clapping, } \\
\text { Arm and leg swings, etc. }\end{array}$ \\
\hline Forest walking & $30 \mathrm{~min}$ & Lakeside walkway & $\begin{array}{l}\text { Listening to the sound of the forest, Looking at } \\
\text { the trees, Feeling the wind, Walking }\end{array}$ \\
\hline Breathing meditation & $10 \mathrm{~min}$ & Pavilion in the heart of the park & $\begin{array}{l}\text { Focusing on breathing with focus on } \\
\text { abdominal breathing }\end{array}$ \\
\hline Forest walking meditation & $30 \mathrm{~min}$ & Around pavilion & $\begin{array}{l}\text { Walking slowly and silently focusing on } \\
\text { abdominal breathing }\end{array}$ \\
\hline Communicating with trees & $10 \mathrm{~min}$ & Cypress forest & Tree hugging, Observing the shape of trees \\
\hline Natural oil hand massage & $20 \mathrm{~min}$ & Pavilion in the heart of the park & Giving hand massages with aromatic oil \\
\hline Talking about thankfulness & $10 \mathrm{~min}$ & Pavilion in the heart of the park & Talking about three things to be grateful for the past week \\
\hline $\begin{array}{l}\text { Sharing thoughts with others, } \\
\text { Feedback \& Questions }\end{array}$ & $10 \mathrm{~min}$ & Pavilion in the heart of the park & Talking about your experiences and asking questions \\
\hline
\end{tabular}


oversees the mountains in front at a glance as well as a shelter with a cypress forest. It is a quiet place about 30m away from the trail, fascinating the visitors with coherence that provides mental resilience.

\section{Forest healing programs}

The forest healing program consists of two main activities: 'forest walking' and 'meditation.' According to Kim (2017), 'forest walking' in the nature of a forest has the effect of promoting 'emotional and mental' health, and walking is the most common activity among various forest healing activities. Walking in the forest is effective in cognition, emotion and physiology (Martens et al, 2010), and thus highly beneficial both psychologically and mentally. Shin et al. (2013) proved that meditative walking in the forest reduces anxiety and increases self-esteem and happiness. Lee and Shin (2015) stated that forest meditation reduces unnecessary attention and makes people focus on their bodies, thereby awakening the five senses of the human body and promoting the therapeutic effect through the healing factors of the forest such as fragrance and landscape. Lee et al. (2011) claimed that forest meditation is a way to more actively use the healing factors of the forest and can promote the forest healing effect by applying to various forest activities such as listening to the valley stream, taking deep breaths, smelling pine, and looking at trees. Accordingly, we organized the program with focus on 'forest walking' and 'meditation' as shown in Tables 1 and 2.

\section{Measurement tool}

This study measured the resilience quotient before and after the program to examine the effects of the forest healing program on resilience in the elderly. We used the Korean Resilience Quotient-53 (KRQ-53) developed for Koreans by Kim (2011) based on the Resilience Quotient Test (RQT) developed in 2003 by Reivich \& Shatte. It consists of total 53 items to be rated on a 5-point Likert scale (1=strongly disagree; $5=$ strongly agree), and higher sum indicates higher resilience.

The subfields consist of 18 items of self-regulation ability (affect regulation ability, impulse control ability, causal analysis ability), 18 items of interpersonal ability (communication, empathy, self-expansion), and 17 items of affirmative ability (self-optimism, life satisfaction, gratitude). Higher sum indicates higher self-regulation ability, interpersonal ability and affirmative ability. In the study by Han (2015), the reliability of this scale was Cronbach's $\alpha=.924$, and as a result of verifying the reliability of this scale in this study, it was Cronbach's $\alpha=.866$. For each subfactor, the self-regulation ability is .750, interpersonal ability is .719, and affirmative ability is .776, as shown in Table 3 .

\section{Data processing method}

The data measured in this study was analyzed using the statistical program SPSS ver. 21.0 (IBM, Amonk, NY, USA). Descriptive statistics were used for the characteristics of the subjects, and a paired sample t-test is used to test the resilience

Table 3. The reliability coefficient for the sub-factors of the resilience measure of the forest healing program for the elderly

\begin{tabular}{llccc}
\hline & Variable & Number of items & Question number & Cronbach's $\alpha$ \\
\hline \multirow{3}{*}{ Resilience } & Self-regulation ability & 18 & $1 \sim 18$ & .750 \\
& Interpersonal ability & 18 & $19 \sim 36$ & .719 \\
& Positivity & 17 & $37 \sim 53$ & .776 \\
\hline
\end{tabular}


before and after the forest healing program, with the significance level of $p<.05$.

\section{Results and Discussion}

\section{General characteristics of subjects}

Table 4 shows the demographic and general characteristics of the experimental group. The mean age was $71.45 \pm 3.11$ (age 66-75), and there were 5 male and 15 female participants. Fourteen (70\%) of them were either married or living together, and six of them were living alone due to divorce or bereavement. Ten of them were high school graduates or higher, and ten were middle school graduates or lower. Fourteen participants (70\%) were healthy, and $11(55 \%)$ of them had 'average' standard of living.

\section{Pretest-posttest of resilience}

\section{Resilience}

The sum of the scores for self-regulation ability, interpersonal ability and positivity is the resilience quotient. To verify whether the forest healing program has effects on resilience before and after the experiment, we used the paired samples t-test for analysis. We also conducted the Shapiro-Wilk test that is designed for cases in which there are less than 50 samples for test of normality, and found that the samples are in normal distribution. Resilience of the elderly increased from before $(168.4, \mathrm{SD}=14.372)$ to after the program $(178.0, \mathrm{SD}=16.524)$ as shown in Table 5 , and there was a significant

Table 4. General characteristics of elderly participants $(\mathrm{N}=20)$

\begin{tabular}{cccc}
\hline Characteristic & Category & $\mathrm{n}(\%)$ & $\mathrm{M} \pm \mathrm{SD}$ \\
\hline \multirow{2}{*}{ Sex } & Male & $5(25 \%)$ & $15(75 \%)$ \\
& Female & & $71.45 \pm 3.11$ \\
\hline Age & Range 66-75 & $14(70 \%)$ & $6(30 \%)$ \\
Marital status & Married & $6(30 \%)$ & $4(20 \%)$ \\
& Single & $5(25 \%)$ & $5(25 \%)$ \\
Education level & Elementary & $2(10 \%)$ & $11(55 \%)$ \\
& Middle school & $7(35 \%)$ \\
\hline Health Status & High School & $5(25 \%)$ \\
& College or university & $11(55 \%)$ \\
\hline
\end{tabular}

Table 5. Resilience effect of forest healing programs for elderly people

\begin{tabular}{ccccccc}
\hline & $\mathrm{N}$ & $\mathrm{M}$ & $\mathrm{SD}$ & $\mathrm{df}$ & $\mathrm{t}$ & $p$ \\
\hline Pre & 20 & 168.400 & 14.372 & \multirow{2}{*}{19} & -4.554 & $.000^{*}$ \\
Post & 20 & 178.000 & 16.524 & & & \\
\hline
\end{tabular}

" $p<.05$ by paired t-test 
result in $\mathrm{t}=-4.554, p<.05$, proving that the forest healing program is effective for increasing resilience in the elderly.

\section{1) Self-regulation ability}

Self-regulation ability is the sum of three sub-factors that are emotion regulation ability, impulse control ability, and cause analysis ability. We used the paired samples t-test to verify whether the forest healing program has effects on self-regulation ability before and after the experiment. Self-regulation ability of the elderly increased from before (56.3, $\mathrm{SD}=6.621)$ to after the program $(59.8, \mathrm{SD}=6.682)$ as shown in Table 6 , and there was a significant result in $\mathrm{t}=-2.630$, $p<.05$. Impulse control ability also showed a significant increase.

\section{2) Interpersonal ability}

Interpersonal ability is the sum of three sub-factors that are communication ability, empathy ability, and self-expansion. We used the paired samples t-test to verify whether the forest healing program has effects on interpersonal ability before and after the experiment. Interpersonal ability of the elderly increased from before $(56.2, \mathrm{SD}=5.717)$ to after the program (60.3, $\mathrm{SD}=5.795$ ) as shown in Table 7 , and there was a significant result in $\mathrm{t}=-4.080, p<.05$. Empathy ability and self-expansion also showed a significant increase.

\section{3) Positivity}

Positivity is measured by the attitude to see one's own advantages and strengths optimistically, satisfaction with life that

Table 6. Self-regulation ability effect of forest healing program for elderly people

\begin{tabular}{|c|c|c|c|c|c|c|c|}
\hline Factor & & $\mathrm{N}$ & M & SD & df & $\mathrm{t}$ & $p$ \\
\hline \multirow{2}{*}{ Self-regulation ability } & Pre & 20 & 56.550 & 6.621 & \multirow{2}{*}{19} & \multirow{2}{*}{-2.630} & \multirow{2}{*}{$.016^{*}$} \\
\hline & Post & 20 & 59.850 & 6.682 & & & \\
\hline \multirow{2}{*}{ Emotion control ability } & Pre & 20 & 19.3 & 2.556 & \multirow{2}{*}{19} & \multirow{2}{*}{-2.630} & \multirow{2}{*}{.181} \\
\hline & Post & 20 & 19.9 & 2.221 & & & \\
\hline \multirow{2}{*}{ Impulse control ability } & Pre & 20 & 18.45 & 2.543 & \multirow{2}{*}{19} & \multirow{2}{*}{-1.390} & \multirow{2}{*}{$.009^{*}$} \\
\hline & Post & 20 & 19.65 & 2.621 & & & \\
\hline \multirow{2}{*}{ Cause analysis ability } & Pre & 20 & 19.9 & 3.432 & \multirow{2}{*}{19} & \multirow{2}{*}{-.804} & \multirow{2}{*}{.431} \\
\hline & Post & 20 & 20.35 & 2.852 & & & \\
\hline
\end{tabular}

${ }^{*} p<.05$ by paired t-test

Table 7. Interpersonal ability effect of forest healing program for elderly people

\begin{tabular}{|c|c|c|c|c|c|c|c|}
\hline Factor & & $\mathrm{N}$ & M & SD & df & $\mathrm{t}$ & $p$ \\
\hline \multirow{2}{*}{ Interpersonal ability } & Pre & 20 & 56.200 & 5.717 & \multirow{2}{*}{19} & \multirow{2}{*}{-4.080} & \multirow{2}{*}{$.001^{*}$} \\
\hline & Post & 20 & 60.300 & 5.795 & & & \\
\hline \multirow{2}{*}{ Communication ability } & Pre & 20 & 18.8 & 2.397 & \multirow{2}{*}{19} & \multirow{2}{*}{-2.077} & \multirow{2}{*}{.052} \\
\hline & Post & 20 & 19.95 & 2.211 & & & \\
\hline \multirow{2}{*}{ Empathy ability } & Pre & 20 & 18.55 & 2.372 & \multirow{2}{*}{19} & \multirow{2}{*}{-4.125} & \multirow{2}{*}{$.001^{*}$} \\
\hline & Post & 20 & 20.00 & 2.152 & & & \\
\hline \multirow{2}{*}{ Self-expansion ability } & Pre & 20 & 18.85 & 2.996 & \multirow{2}{*}{19} & \multirow{2}{*}{-3.899} & \multirow{2}{*}{$.001^{*}$} \\
\hline & Post & 20 & 20.85 & 1.980 & & & \\
\hline
\end{tabular}

${ }^{*} p<.05$ by paired t-test 
is the fundamental level of happiness, and gratitude toward life and others. We used the paired samples t-test to verify whether the forest healing program has effects on positivity before and after the experiment. Positivity of the elderly increased from before (55.65, $\mathrm{SD}=5.556)$ to after the program $(57.85, \mathrm{SD}=5.896)$ as shown in Table 8 , but it was not significant in $\mathrm{t}=-1.749, p<.05$. Self-optimism and gratitude also showed a significant increase, while life satisfaction showed a decrease.

\section{Discussions}

With the acceleration of the aging society, there is a need for measures to improve the life satisfaction of the elderly population to relieve depressive mood caused by stress in life such as economic stability, health and relationship with children. Accordingly, we studied the effects of a forest healing program using an urban forest on resilience of the elderly, and the results are as follows. In all categories such as resilience of the participants in the forest healing program as well as sub-factors such as self-regulation ability, interpersonal ability and positivity, the mean scores increased in the posttest compared to the pretest. Except for positivity, self-regulation ability and interpersonal ability both had statistically significant effects. The experiment result of resilience shows that the surrounding vegetation, landscape, well-organized trail, central lake, and shelter that oversees the lake at the study area all serve as cohesive and attractive factors to naturally see and understand the environment without much effort, thereby reducing stress and attention fatigue, providing physiological and psychological comfort, showing psychological recovery effect and improving resilience. This is in line with the study by Park and Lee (2016) proving that a forest must have enable visitors to be mentally away to give satisfaction and psychological resilience, coherence among components in the healing environment, and that a natural forest path and shelter have high therapeutic effects, and also with the study by Yi (2006) that landscapes create involuntary attention with the fascination factor and this recovers concentration. Leisure activities in urban parks are closely related to resilience (van Kessel, 2013), and leisure activities in nature such as walking enable interaction with the natural environment, which can be systematic training to improve resilience (Kim, 2014). The elderly engaged in leisure activities are more likely to age successfully if they have higher resilience (Yi and Ahn, 2010). The elderly engaged in leisure activities have less life stress and depression, and thus their resilience increases (Choi and Lee, 2012). This is in line with previous studies such as the one revealing that the forest healing program is a suitable activity to promote mental health for the elderly and the need to apply forest healing using urban forests within the life zone (Kim et al., 2017). The forest healing program uses the psychological healing method such as 'forest walking' and 'meditation' and forest healing

Table 8. Positivity effect of forest healing program for elderly people

\begin{tabular}{|c|c|c|c|c|c|c|c|}
\hline Factor & & $\mathrm{N}$ & M & SD & df & $\mathrm{t}$ & $p$ \\
\hline \multirow{2}{*}{ Positivity } & Pre & 20 & 55.650 & 5.556 & \multirow{2}{*}{19} & \multirow{2}{*}{-1.749} & \multirow{2}{*}{.096} \\
\hline & Post & 20 & 57.850 & 5.896 & & & \\
\hline \multirow{2}{*}{ Self-optimism } & Pre & 20 & 19.75 & 1.943 & \multirow{2}{*}{19} & \multirow{2}{*}{-2.113} & \multirow{2}{*}{$.048^{*}$} \\
\hline & Post & 20 & 20.90 & 2.693 & & & \\
\hline \multirow{2}{*}{ Life satisfaction } & Pre & 20 & 16.10 & 2.593 & \multirow{2}{*}{19} & \multirow{2}{*}{.804} & \multirow{2}{*}{.431} \\
\hline & Post & 20 & 15.40 & 2.799 & & & \\
\hline \multirow{2}{*}{ Gratitude } & Pre & 20 & 20.15 & 1.980 & \multirow{2}{*}{19} & \multirow{2}{*}{-2.746} & \multirow{2}{*}{.013} \\
\hline & Post & 20 & 21.55 & 2.564 & & & \\
\hline
\end{tabular}

${ }^{*} p<.05$ by paired t-test 
factors that enable people to easily access forest healing in daily life by looking at oneself away from the stress of physical, mental and emotional stimulation in urbanized life. This program improved resilience with the effect of promoting emotions or feelings by recovering the lack of attention for the elderly. The resilience experiment results can be summarized as follows according to each subfactor.

\section{Self-regulation ability}

Self-regulation ability showed increase in all sub-factors such as emotion regulation ability, impulse control ability, and cause analysis ability. Impulse control ability showed a statistically significant result. Walking in the forest using the environmental factors of the forest with good vegetation and fascination of landscape overlooking the lake and being away from daily life provides psychological resilience and satisfaction. The healing program gives mental stability and positive emotions, thereby improving self-regulation ability and exerting more effect on impulse control ability. As shown in the study by Astell-Burt et al. (2013) proving that green space is important for promoting physical activities of adults that are middle aged or older, and the mental health benefits of the environment vary according to active method of activities. As such, forest healing programs in urban forests have considerable effects on not only physical activities but also mental health, and meditation in urban parks provides an opportunity for introspection, looking into not only one's environment but also oneself (Mayer et al., 2009). Physical activities in the natural environment have a positive effect on the psychological aspect such as improving self-esteem and refreshing one's mood (Yamaguchi et al., 2006). It was found that walking in the forest is effective on cognitive, emotional and physiological aspects and thus highly beneficial both psychologically and mentally. The results supported previous studies proving that meditative walking in the forest reduces anxiety and increases self-esteem and happiness, and the stimulation of the five senses with the forest healing factors gives pleasure to the brain, thereby relieving anger and anxiety, making people love not only themselves but others as well, and gain self-esteem and happiness (Kim, 2017). Moreover, the experiment by Sonntag-Östroöm et al. (2011) evaluating the possibility that forests can be used in rehabilitation of stress-related fatigue disorders pointed out that lakeside forests are preferred most by the participants, used the most positive terms such as light, brightness, sun and open topography, and claimed that the participants was most grateful for serenity at the forest. As such, the study area in this experiment has an open landscape overlooking the lake, and thus had more effect on improving self-regulation ability of the participants.

\section{Interpersonal ability}

Interpersonal ability showed increase in all sub-factors such as communication ability, empathy ability, and self-expansion. Empathy ability and self-expansion showed a statistically significant increase. Zhang et al. (2015) claimed that high-quality greens that are accessible and available form an emotional bond with residents. Moreover, as people naturally assimilate with the natural environment in the urban park, they can have the chance to positively change their negative perception of themselves and their surroundings (Kim, 2014). Forest therapy enables people to overcome daily difficulties by providing generosity, courage and insight (Shin et al., 2015). Previous research proved that forest experience of adolescents improved various factors in the mental health scale such as somatization, hostility and interpersonal sensitivity (Shin et al., 2008). As such, forest healing programs such as forest walking and meditation in an urban natural park that is accessible from the city help people feel united with nature through the natural environment and connected with their surroundings through forest activities carried out with others, thereby increasing interpersonal ability.

\section{Positivity}

Positivity showed increase in sub-factors such as self-optimism and gratitude, but decrease in life satisfaction. Thus, the 
overall positivity showed an increase, but the result was not statistically significant. As for life satisfaction, the demographic survey showed that $20 \%$ of all participants responded that their living environment was 'poor' and $55 \%$ said it was 'average,' showing the effect of their current financial conditions. Thus, a short-term forest healing program is not enough to increase life satisfaction, but showed a significant increase in self-optimism and gratitude, which indicates that applying a long-term program will lead to a significant improvement. The cause of increase in self-optimism and gratitude can be proved by the study that the physical, mental and environmental factors of urban forests are deeply correlated with health of the elderly and affect the quality of life (Kim, 2013). As such, forest walking and meditation create unity with nature and the forest environment attracts individual interest, reducing their concentration on problems in daily life and replacing their pessimistic thoughts naturally with positive thoughts. As proved by Lee et al. (2003) that people showed increased happiness and self-esteem after being exposed to a forest, and by Kim and Kim (2015) that people's activities in nature affect positive emotions and attitudes with the resilience and comfort provided by nature, positive emotions from exposure to and activities at urban forests affected self-optimism and gratitude.

\section{Conclusion}

Depression, which has a negative effect on the quality of elderly life, causes the elderly to live an impoverished life and leads to elderly suicide. To prevent these symptoms of elderly depression, improving resilience may be one way for them to overcome physical and mental depression and tress caused by aging and improve the quality of life. However, mental health programs or resilience improvement programs in nature are insufficient. Accordingly, we aimed to determine the effects of forest healing programs on improving resilience at urban forests, and propose forest healing as an activity to promote mental resilience of the elderly according to aging.

The results of this study showed that resilience increased after two weeks of the forest healing program on the elderly at an urban forest. Moreover, subfactors of resilience such as self-regulation ability, interpersonal ability and positivity were also increased. Based on these results, this study proves that it is necessary to apply forest healing using urban forests and that a forest healing program is a suitable activity to improve resilience for the mental health of the elderly. Therefore, forest healing programs using urban forests that are accessible from living space give the elderly a chance to visit the forests often and provide them with ways to recover their mental health related to stress.

Recently, public institutions such as health clinics of local governments or health insurance services carry out many programs for the mental and physical health of the elderly, but most of them are health programs inside the public institutions, senior citizen centers, or spaces around the village. Therefore, by expanding these health promotion programs for the elderly to forest healing programs using urban forests, and making this regular in connection with elderly health promotion or welfare policies, it will be helpful for solving social and economic problems in the aging society.

This study conducted the experiment on only a limited scope of the elderly and does cannot represent all of the elderly population. Moreover, the program was held in a short period, and thus cannot predict consistent effect despite the verified effect on the improvement of resilience for the elderly. For more precise analysis, it is necessary to observe and conduct a follow-up inspection for a certain period of time to analyze the effects by program running period, gender and individual difference, and to determine more specific and constant effects.

\section{References}

Astell-Burt, T., X. Feng, and G.S. Kolt. 2013. Mental health benefits of neighbourhood green space are stronger among 
physically active adults in middle-to-older age: Evidence from 260,061 Australians. Prev. Med. 57(5):601-606. DOI:10.1016/j.ypmed.2013.08.017

Choi, G.H. 2013. A study on the effect analysis of forest healing -Focused on senior citizens-. Master's thesis, Jeonbuk National University, Jeonju, Korea.

Choi, M.R. and Y.C. Lee. 2012. The leisure sports participation, life stress, depression and buffering effect of resilience among the elderly. Korean J. Phys. Educ. 51(1):75-90.

Han, S.Y. 2015. Resilience, the relationship between work-life balance and job satisfaction. Master's thesis, Korea University, Seoul, Korea.

Hong, E.S. 2006. Conceptual understanding of resilience and instructional suggestion. Korean J. Spec. Educ. 41(2):45-67.

Jung, M.K. 2010. A study on resilience of old age: On the focus of loss experience and ego-Integrity. Doctoral dissertation, Ajou University, Suwon, Korea.

KiHASA(Korea institute for Health and Social Affairs). 2010. Research Report, 2010-24. Retrieved from www.kihasa.re.kr

Kim, G.H. 2014. Analysis of the effects of leisure satisfaction in urban parks on work stress and the resilience of office workers:The mediative effect of psychological detachment. Doctoral dissertation, Sejong University, Seoul, Korea.

Kim. J.H. 2011. Resilience. Goyang. Korea: Wisdumhause.

Kim, J.O. and N.J. Kim. 2015. The effect of the attractiveness of nature on attitude and behavioral intention in outdoor recreation -Focused on cognitive and affective attitude-. J. Tour. Stu. (by The Hanyang Tourism Research Institute) 27(1):75-97.

Kim, J.Y., C.S. Shin, and J.K. Lee. 2017. The effects of forest healing program on mental health and melatonin of the elderly in the urban forest. Doctoral dissertation, Chungbuk National University, Cheongju, Korea.

Kim, K.W. 2017. Theoretical study on modern interpretation and therapeutic application of xiaoyoyu (happy wandering) in Zhuangzi. J. Korean Inst. For. Recreat. 21(1):1-15.

Kim, Y.R. 2013. The relationship between urban forest use and senior citizen's social bonding and QOL. Master's thesis, Chungbuk National University, Cheongju, Korea.

Korea Forest Service. 2016. Forest basic statistics. Retrieved from www.forest.go.kr

KOSIS(Korean Statistical information service). 2014. Survey of the elderly. Retrieved from www.kosis.kr

KOSIS(Korean Statistical information service). 2018. Elderly people status. Retrieved from www.kosis.kr

Kwon, G.C. and J.S. Choi. 2016. Forest healing program development for realization of forest welfare service for the elderly on the aging society. J. Korean Soc. Beauty Art 17(1):249-263.

Lee, E.D., S.J. Park, R.H. Yoo, and S.J. Hong. 2011. Analysis on the activity contents of forest healing programs in Korea. J. Korean Inst. For. Recreat. 15(2):101-109.

Lee, S.I., W.S. Shin, Y.M. Kown, and H.G. Kwon. 2003. The effect of woods aromatic substance. J. Korean Inst. For. Recreat. 7(4):25-29.

Lee, Y.J. and C.S. Shin. 2015. Effects of forest walking meditation on mood states and self-awareness in middle-aged women. J. Korean Inst. For. Recreat. 19(3):19-25.

Martens, D., H. Gutscher, and N. Bauer. 2010. Walking in "wild" and "tended" urban forests: the impact on psychological well-being. J. Environ. Psychol. 31(1):36-44. DOI:10.1016/j.jenvp.2010.11.001

Mayer, F.S., C.M. Frantz, E. Bruehlman-Senecal, and K. Dolliver. 2009. Why is nature beneficial? The role of connectedness to nature. Environ. Behav. 41(5):607-643. DOI:10.1177/0013916508319745

Park, B.J. and Y. Miyazaki. 2008. Physiological effects of viewing forest landscapes: results of field tests in Atsugi city, Japan. J. Korean For. Soc. 97(6):634-640.

Park, J.S., Y.K. Park, S.H. Jung, C.S. Lee, and H. Kim. 2014. Influence of resilience and depression on suicidal ideation in elderly. J. Korean Gerontol. Soc. 34(2):247-258.

Park, S.A. and M.W. Lee. 2016. An analysis of the healing effects by types of forest space- Focused on psychological 
restorativeness and satisfaction-. J. Korean Inst. Landsc. Archit. 44(4):75-85.

Shin, C.S., P.S. Yeon, M.N. Jo, and J.Y. Kim. 2015. Effects of forest healing activity on women's menopausal symptoms and mental health recovery. J. Korean Soc. People Plants Environ. 18(4):319-325.

Shin, W.S., S.I. Lee, J.H. Ryu, and E.W. Lee. 2008. The influence of forest experience on the mental health. J. Korean Inst. For. Recreat. 4(1·2):25-32.

Shin, Y.K., D.J. Kim, K.H. Jung-Choi, Y.J. Son, J.W. Koo, J.A. Min, and J.H. Chae. 2013. Differences of psychological effects between meditative and athletic walking in a forest and gymnasium. Scandinavian J. For. Res. 28(1):64-72. DOI:10.1080/02827581.2012.706634

Sonntag-Östroöm, E., M. Mordin, L.S. Järvholm, Y, Lundell, R. brännström, and A. Dollig. 2011. Can the boreal forest be used for rehabilitation and recovery from stress-related exhaustion? A pilot study. Scandinavian. J. For. Res. 26(3):245-256. DOI:10.1080/02827581.2011.558521

van Kessel, G. 2013. The ability of older people to over come adversity: A review of the resilience concept. Geriatr. Nurs. 34(2):122-127. DOI:10.1016/j.gerinurse.2012.12.011

Yamaguchi, M., M. Deguchi, and Y. Miyazaki. 2006. The effects of exercise in forest and urban environments on sympathetic nervous activity of normal young adults. J. Int. Med. Res. 34(2):152-159.

Yi, E.S. and C.W. Ahn. 2010. Effect of leisure sports participation on the successful aging of elderly: analysis of the intermediating effect of resilience. Korean J. Phys. Educ. 49(4):325-337.

Yi, Y.K. 2006. Influence of the restorative quality of landscape on the visiting preference and satisfaction for tourist destination - an evaluation of heritage landscape of Kyongju by Americans -. J. Korean Inst. Landsc. Archit. 34(5):1-13.

Yoon, H.S. and S.R. Yoon. 2017. The mediating effects of resilience on depression and suicidal ideation of older adults in korea. Korean J. Gerontol. Soc. Welf. 72(1):233-255.

Zhang, Y., T.V. Dijk, J. Tang, and A.E. van den Berg. 2015. Green space attachment and health: a comparative study in two urban neighborhoods. Int. J. Environ. Res. Public Health 12(11):14342-14363. DOI:10.3390/ijerph121114342 
